\title{
Effect of bovine colostrum supplementation on cytokine mRNA expression in weaned piglets
}

\author{
C. Boudry ${ }^{\mathrm{a}}$, A. Buldgen ${ }^{\mathrm{a}}$, D. Portetelle ${ }^{\mathrm{b}}$, P. Gianello ${ }^{\mathrm{c}}$, A. Théwis ${ }^{\mathrm{a}}$, P. Leterme ${ }^{\mathrm{d}}$, J.P Dehoux $^{\mathrm{c}}$ \\ ${ }^{a}$ Unité de Zootechnie, Faculté Universitaire des Sciences Agronomiques, Passage des Déportés 2, 5030 Gembloux, Belgium \\ ${ }^{b}$ Unité de Biologie Animale et Microbienne, Faculté Universitaire des Sciences Agronomiques, Passage des Déportés 2, 5030 Gembloux, \\ Belgium \\ ${ }^{c}$ Unité de Chirurgie expérimentale, Faculté de Médecine, Université catholique de Louvain, Avenue Hippocrate 55/70, 1200 Brussels, \\ Belgium \\ ${ }^{d}$ Prairie Swine Centre, 2105 8th Street East, Saskatoon, SK, Canada S7H 5N9
}

\begin{abstract}
The aim of this study was to evaluate the influence of bovine colostrum supplementation on the immune Th1/Th2 response in weaned piglets. After weaning at $21 \mathrm{~d}, 3$ groups of 7 piglets were fed ad libitum with a starter diet and received daily 0,1 or $5 \mathrm{~g}$ of spray-dried bovine colostrum. Spleen and gut-associated lymphoid tissues (GALT): ileal Peyer's patch (iPP), jejunum wall (JW) and mesenteric lymph node (MLN)) biopsies were collected on each piglet after $3 \mathrm{wk}$ of treatment and analysed for their cytokine mRNA expression (IL-2, IL-4, IL-10, IL-12 and IFN- $\gamma$ ) by RT-PCR. The supplementation with bovine colostrum induced an increase $(P<0.05)$ in IL-12 in the JW, in IL-2, IL-10 and IL-12 in the MLN and in IL-4, IL-10 and IL-12 in the iPP. In the latter, bovine colostrum also decreased IFN- $\gamma$ production $(P<0.01)$. Finally, no effect of the treatments was recorded in the spleen. These results suggest an immunomodulatory effect of bovine colostrum on the GALT, which responded by producing at different levels both Th1 pro-inflammatory cytokines (IL-2, IFN- $\gamma$ and IL-12) and Th2 anti-inflammatory cytokines (IL-4 and IL-10). This Th1/ Th2 bipolar response protects the weaned piglets from both allergic (food) and infectious (pathogens) diseases.
\end{abstract}

Keywords: Piglet; Bovine colostrum; Cytokine; Th1/Th2; RT-PCR

\section{Introduction}

Bovine colostrum has a critical role in post-neonatal health as an immune booster. In addition to its content in nutrients, it also provides growth and anti-microbial factors that, respectively, promote the growth and the development of the newborn calf and protect against infections during the first week of life (Mero et al., 1997; Pakkanen and Aalto, 1997).

The most abundant and well-characterized growth factors in bovine colostrum are insulin-like growth factors (IGF-1 and IGF-2), insulin, transforming growth factors (TGF- $\beta 1$ and TGF- $\beta 2$ ) and epidermal growth factors (EGF). Anti-microbial factors include immunoglobulins, lactoferrin, lysozyme and lactoperoxidase (Pakkanen and Aalto, 1997).

Weaning is a major critical period of pig production because of increased susceptibility to gut disorders, infections and diarrhoea due to psychological, social, environmental and dietary stresses interfering with gut development and adaptation (Pluske et al., 1997). This period is also correlated with an inflammation of the gut involving some alterations of the intestinal immunity and the immune responses against dietary and bacterial antigens (Hannant, 2002).

Bovine colostrum has been used as a health food supplement for humans. It limits diarrhoea in patients suffering from immunodeficiency syndromes, inflammatory colitis, or acute phase-responses to surgery (He et al., 2001). The mechanisms by which bovine colostrum protects the host from infections are attributed to the antimicrobial action of its functional components on infective agents and toxins and/or on host immune responses.

Nevertheless, the data available on the immunomodulatory effects of bovine colostrum in non-ruminants (as well 
as human subjects) are still limited.

The aim of this study was to determine the effects of orally administered bovine colostrum ( 0,1 and $5 \mathrm{~g}$ daily) on the immune Th1/Th2 response in weaned piglets.

\section{Material and methods}

\subsection{Animals, diet and experimental design}

Twenty-one 3-week-old newly weaned Belgian Landrace male piglets (Gentec NV, Buggenhout, Belgium) weighing $7.4 \pm 0.4 \mathrm{~kg}$ were randomly allocated among three groups. Each group was fed ad libitum with the same diet (crude proteins, 20.1\%; net energy, $2050 \mathrm{kcal} / \mathrm{kg}$ ) and the piglets of the different groups received daily a solution containing $0 \mathrm{~g}$ (Group 0), $1 \mathrm{~g}$ (Group 1) or $5 \mathrm{~g}$ (Group 5) of spray-dried bovine colostrum (CER, Marloie, Belgium) for $3 \mathrm{wk}$. Colostrum solutions were prepared by dissolving the colostrum in water at a concentration of $10 \%(\mathrm{w} / \mathrm{v})$ and administered into the buchal cavity of each piglet each morning.

On day 21, the animals were anaesthetized and biopsies of the mesenteric lymph nodes (MLN), jejunum wall (JW) ( $100 \mathrm{~cm}$ after pylorus), ileal Peyer' s patch (iPP) and spleen were collected and immediately frozen in liquid nitrogen before storing at $-80^{\circ} \mathrm{C}$. Piglets were then seacrificed. All procedures were handled according to the guidelines established by the ethical committee of the Catholic University of Louvain (Belgium) and the Belgian legislation about care and use of laboratory animals.

\subsection{RNA extraction and analysis by real-time PCR (RT-PCR)}

Total RNA was extracted from the frozen biopsies $(400 \mathrm{mg}$ ) with TriPure Isolation Reagent (Roche Diagnostics Corporation, Indianapolis, IN, USA), according to the instructions of the manufacturer. RNA was quantified by spectrophotometry $(\lambda=260 \mathrm{~nm})$. Reverse transcription (RT) was performed on $1 \mu \mathrm{g}$ of total RNA in a reaction volume of $20 \mu 1$ involving random hexamers, RT buffer $5 \mathrm{X}, 9 \mathrm{mM}$ dithiothreitol, $220 \mu \mathrm{M}$ of each deoxyribonucleotide triphosphate (dNTP) and $200 \mathrm{U}$ of M-MLV (Invitrogen, California, USA). Final RT product was adjusted to $50 \mu \mathrm{l}$ using RNase free water. cDNA product was amplified on a GeneAmp 5700 Sequence Detection System and software (Applied Biosystems, Den Ijssel, the Netherlands) using SYBR Green detection (Applied Biosystems, Foster City, CA, USA). RT-PCR was carried out using the following cycle parameters: $10 \mathrm{~min}$ at $95{ }^{\circ} \mathrm{C}$, followed by 50 cycles of $1 \mathrm{~min}$ at $60^{\circ} \mathrm{C}$ and $15 \mathrm{~s}$ at $95{ }^{\circ} \mathrm{C}$. The following primers were used:

- for IL2, forward: CAGTTGCTTTTGAAGGAAGT-TAAGAA; reverse: GCCTGCTTGGGCATGTAAA;

- for IL-12: forward: CGTGCCTCGGGCAATTA-TAA; reverse: CAGGTGAGGTCGCTAGTTTGG;

- for IFN $\gamma$, forward: TTCAAAGATAACCAGGC-CATTCA; reverse: CACTGATGGCTTTGCGCTG;

- for IL-4, forward: CACAGCGAGAAAGAACTCGT; reverse: GTCCGCTCAGGAGGCTCTTC;

- for IL-10, forward: CTTGTTGCTGACCGGGTCTCT; reverse: TCGGCATTACGTCTTCCAGGT.

The ribosomal protein L19 (RPL19) RNA was chosen as an internal standard reporter gene (forward primer: CAAGCGGATTCTCATGGAACA; reverse primer: TGGTCAGCCAGGAGCTTCTT). Results were expressed relative to the internal standard RPL19 and to the Group 0, using the comparative cycle threshold method (User Bulletin \#2, Applied Biosystems). 
Table 1. Cytokines expression (mRNA of cytokine/mRNA of RPL19 reporter gene) in tissues ${ }^{l}$ coming from animals that received daily $0 \mathrm{~g}$ (Group 0), $1 \mathrm{~g}$ (Group 1) or $5 \mathrm{~g}$ (Group 5) of bovine colostrum for 3 wk $(n=7)$

\begin{tabular}{|c|c|c|c|c|c|}
\hline \multirow{2}{*}{\begin{tabular}{|l|} 
Cytokine \\
\end{tabular}} & \multirow[b]{2}{*}{ Tissue $^{1}$} & \multicolumn{3}{|c|}{ Treatment group } & \multirow[b]{2}{*}{ SEM } \\
\hline & & 0 & 1 & 5 & \\
\hline \multirow[t]{4}{*}{ IL-2 } & JW & 1.00 & 1.07 & 1.19 & 0.91 \\
\hline & MLN & $1.00^{\mathrm{a}}$ & $1.23^{\mathrm{a}}$ & $3.20^{\mathrm{b}}$ & 0.71 \\
\hline & iPP & 1.00 & 0.92 & 1.90 & 0.81 \\
\hline & Spleen & 1.00 & 1.05 & 0.98 & 0.63 \\
\hline \multirow[t]{4}{*}{ IL-12 } & JW & $1.00^{\mathrm{a}}$ & $2.65^{\mathrm{a}}$ & $4.10^{b}$ & 1.33 \\
\hline & MLN & $1.00^{\mathrm{a}}$ & $1.34^{\mathrm{a}}$ & $3.18^{b}$ & 1.00 \\
\hline & iPP & $1.00^{\mathrm{a}}$ & $1.83^{\mathrm{a}}$ & $4.24^{\mathrm{b}}$ & 1.38 \\
\hline & Spleen & 1.00 & 0.77 & 0.91 & 0.98 \\
\hline \multirow[t]{4}{*}{ IFN-Y } & JW & 1.00 & 1.75 & 2.47 & 0.88 \\
\hline & MLN & 1.00 & 1.36 & 1.26 & 0.65 \\
\hline & iPP & $1.00^{\mathrm{a}}$ & $0.76^{\mathrm{ab}}$ & $0.46^{\mathrm{b}}$ & 0.75 \\
\hline & Spleen & 1.00 & 0.75 & 0.80 & 0.54 \\
\hline \multirow[t]{4}{*}{ IL-4 } & JW & 1.00 & 0.79 & 0.69 & 0.64 \\
\hline & MLN & 1.00 & 0.77 & 1.11 & 0.73 \\
\hline & iPP & $1.00^{\mathrm{a}}$ & $3.65^{b}$ & $4.56^{b}$ & 0.76 \\
\hline & Spleen & 1.00 & 0.74 & 0.80 & 0.78 \\
\hline \multirow[t]{4}{*}{ IL-10 } & JW & 1.00 & 0.83 & 0.79 & 0.91 \\
\hline & MLN & $1.00^{\mathrm{a}}$ & $2.99^{b}$ & $2.11^{\mathrm{ab}}$ & 0.83 \\
\hline & iPP & $1.00^{\mathrm{a}}$ & $3.30^{b}$ & $2.9 \mathrm{l}^{\mathrm{ab}}$ & 1.49 \\
\hline & Spleen & 1.00 & 1.08 & 1.09 & 0.72 \\
\hline
\end{tabular}

abans in the same line with different superscripts are different $(P<0.05)$.

${ }^{I} \mathrm{JW}=$ jejunum wall, $M L N=$ mesenteric lymph node, $i P P=$ ileal Peyer's patch.

\subsection{Statistical analysis}

The statistical differences between the groups were tested using the one-way analysis of variance, followed by Student's $t$-test.

\section{Results}

The results of cytokine mRNA expressions are presented in Table 1. The supplementation with bovine colostrum induced an increase $(P<0.05)$ in IL-12 in the JW, in IL-2, IL-10 and IL-12 in the MLN and in IL-4, IL-10 and IL-12 in the iPP. A decrease $(P<0.01)$ in IFN- $\gamma$ was also observed in the iPP consecutive to colostrum administration. Most of those responses were observed with the higher colostrum level, except with IL-10 in MLN and iPP where the lower level of colostrum had highest expression, and with IL-4 in iPP where both levels of colostrum increased expression. No effects of the treatments were recorded in the spleen $(P>0.05)$.

\section{Discussion}

The role of cytokines in the regulation and modulation of the immune response has been widely studied since the Th1/Th2 paradigm was postulated (Mosmann et al., 1986). IL-2, IL-12 and IFN- $\gamma$ are considered to be key cytokines in the Th1 response and serve as indicators of cell-mediated responses, whereas IL-4 and IL-10 participate in the Th2 polarization and secretion and suggest humoral responses (Mosmann and Coffman, 1989; Reiner and Seder, 1995).

In the iPP, IL-4 and IL-10 Th2 cytokine mRNA expressions were increased, while Th1 profile was characterized by no significant IL-2 production, impaired IFN- $\gamma$ production and an increase in IL-12 production after oral administration of bovine colostrum. Even if there was an increase in IL-12 production, which is known to have a 
strong ability to suppress IL-4 production (McKnight et al., 1994) and to potentiate the secretion of IFN- $\gamma$ by T cells (Fukoa et al., 2000), these data suggest that IL-4 and IL-10 production may antagonise IL-12-associated immuno-biology. In contrast in the JW, an increase in IL-12 (significant) and IFN- $\gamma$ (not significant) production, and no modification of IL-2, IL-4 and IL-10 productions indicate a Th1 profile. These data confirm the results obtained in adult mice by Yoshioka et al. (2005).

Globally, the results of this study confirm those of Bessler et al. (1993) and Pecquet et al. (1999) and suggest an immunomodulatory effect of bovine colostrum targeting mainly the GALT, which responded by producing at different levels both Th1 pro-inflammatory cytokines (IL-2, IFN- $\gamma$ and IL-12) and anti-inflammatory Th2 cytokines (IL-4 and IL-10). This bipolarity is important in a context of exposure to a wide range of antigens associated with pathogens, commensal bacteria and food.

\section{Conclusion}

The oral administration of bovine colostrum seems to improve and keep the immunological properties of the structures associated with the gastrointestinal tract in weaning piglets by generating different types of responses protecting from infectious and allergic diseases.

\section{Acknowledgement}

This work was supported by the DGA and the DGTRE of the Walloon Region (Belgium).

\section{References}

Bessler, H., Sirota, L., Notti, I., Milo, T., Djaldetti, M., 1993. IL-2 receptor gene expression and IL-2 production by human preterm newborns' cells. Clin. Exp. Immunol. 93, 479-483.

Fukoa, T., Matsuda, S., Koyasu, S., 2000. Synergistic effects of IL-4 and IL-18 on IL-12-dependent IFN- $\gamma$ production by dendritic cells. J. Immunol. 164, 64-71.

Hannant, D., 2002. Mucosal immunology: overview and potential in the veterinary species. Vet. Immunol. Immunopathol. 87, $265-267$.

He, F., Tuomola, E., Arvilommi, H., Salminen, S., 2001. Modulation of human humoral immune response through orally administered bovine colostrum. FEMS Immunol. Med. Microbiol. 31, 93-96.

McKnight, A.J., Zimmer, G.J., Fogelman, I., Wolf, S.F., Abbas, A.K., 1994. Effects of IL-12 on helper T cell-dependent immune responses in vivo. J. Immunol. 152, 2172-2179.

Mero, A., Mikkulainen, FL, Riski, J., Pakkanen, R., Aalto, J., Takala, T., 1997. Effects of bovine colostrum supplementation on serum IGF-I, IgG, hormone, and saliva IgA during training. J. Appl. Physiol. 83, 1144-1151.

Mosmann, T.R., Coffman, R.L., 1989. TH1 and TH2 cells: different patterns of lymphokine secretion lead to different functional properties. Annu. Rev. Immunol. 7, 145-173.

Mosmann, T.R., Cherwinski, H., Bond, M.W., Giedlin, M.A., Coffman, R.L., 1986. Two types of murine helper T cell clone: 1. Definition according to profiles of lymophkine activities and secreted proteins. J. Immunol. 136, 2348-2357.

Pakkanen, R., Aalto, J., 1997. Growth factors and antimicrobial factors of bovine colostrum. Int. Dairy J. 7, $285-297$.

Pecquet, S., Pfeifer, A., Gauldie, S., Fritsche, R., 1999. Immunoglobulin E suppression and cytokine modulation in mice orally tolerized to beta-lactoglobulin. Immunology 96, 278-285.

Pluske, J.R., Hampson, D.J., Williams, L.H., 1997. Factors influencing the structure and function of the small intestine in the weaned pig: a review. Livest. Prod. Sci. 51, 215-236.

Reiner, S.L., Seder, R.A., 1995. T helper cell differentiation in immune response. Curr. Opin. Immunol. 7, $360-366$.

Yoshioka, Y., Kudo, S., Nishimura, H., Yajima, T., Kishihara, K., Saito, K., Suzuki, T., Suzuki, Y, Kuroiwa, S., Yoshikai, Y, 2005. Oral administration of bovine colostrum stimulates intestinal intraepithelial lymphocytes to polarize Thl-type in mice. Int. Immunopharmacol. $5,581-590$. 